\title{
Problem solving as a challenge for mathematics education in The Netherlands
}

\author{
Michiel Doorman · Paul Drijvers · Truus Dekker · \\ Marja van den Heuvel-Panhuizen · Jan de Lange • \\ Monica Wijers
}

Accepted: 8 June 2007 / Published online: 11 July 2007

(C) FIZ Karlsruhe 2007

\begin{abstract}
This paper deals with the challenge to establish problem solving as a living domain in mathematics education in The Netherlands. While serious attempts are made to implement a problem-oriented curriculum based on principles of realistic mathematics education with room for modelling and with integrated use of technology, the PISA 2003 results suggest that this has been successful in educational practice only to a limited extent. The main difficulties encountered include institutional factors such as national examinations and textbooks, and issues concerning design and training. One of the main challenges is the design of good problem solving tasks that are original, nonroutine and new to the students. It is recommended to pay attention to problem solving in primary education and in textbook series, to exploit the benefits of technology for problem solving activities and to use the schools' freedom to organize school-based examinations for types of assessment that are more appropriate for problem solving.
\end{abstract}

Keywords Mathematics education · Problem solving · Realistic mathematics education · Assessment

M. Doorman $(\varangle) \cdot$ P. Drijvers - T. Dekker · M. van den

Heuvel-Panhuizen · J. de Lange - M. Wijers

Freudenthal Institute for Science and Mathematics Education, Utrecht University, PO box 9432 ,

Aidadreef 12, 3506 GK Utrecht, The Netherlands

e-mail: m.doorman@fi.uu.nl

URL: http://www.fisme.uu.nl

P. Drijvers

e-mail: p.drijvers@fi.uu.nl

M. van den Heuvel-Panhuizen

IQB, Humboldt-Universität Berlin, Berlin, Germany

\section{Introduction}

The importance of problem solving in mathematical thinking and thus in mathematics education is obvious to many of us. Already in 1962, Polya described problem solving as a characteristic of human activity:

Solving a problem means finding a way out of a difficulty, a way around an obstacle, attaining an aim which was not immediately attainable. Solving problems is the specific achievement of intelligence, and intelligence is the specific gift of mankind: solving problems can be regarded as the most characteristically human activity. Polya 1962, p. v.

In line with the contribution by Schoenfeld (2007) in this issue, we consider problem solving as the 'art' of dealing with non-trivial problems which do not yet have a known, routine solution strategy to the student, but which provide opportunities for the student to develop new solution strategies. This description distinguishes problem solving from many activities with problems in mathematics courses, with or without context.

Realistic Mathematics Education is a leading view on the learning of mathematics in The Netherlands. As a result, problem solving in our country is often related to solving real world problems. Still, we do want to stress that problem solving is not at all restricted to real world problems; rather, problems emerging from the 'world of mathematics' can be very rich sources for problem solving activities.

The non-routine aspect of a problem is relative to the history of the person who is confronted with it. A problem can be a real problem-solving item for a student today, while the same problem is part of a regular set of items tomorrow. When a student has dealt with an item before, the character of the activity will change. 
Now, having defined our topic, we will first focus on recent developments in mathematics education in the Netherlands.

\section{Problem solving in The Netherlands: a brief history}

As is the case in many countries, problem solving (in the sense of the above definition) was not an explicit part of the mathematics curriculum in The Netherlands until the eighties. In primary education it still is not. For upper secondary level, however, policy makers and math educators realized in the seventies that a serious problem was emerging. The curriculum was well suited for the students who were preparing for science, but not at all for those pursuing an education (or profession) in other domains such as social studies. It was decided that the latter category of students, who struggled with the formal and abstract approach, would be better served with a more problem-oriented approach focusing on applications and mathematical modelling. This also implied, of course, a very different approach to what should be learned and assessed. The science-oriented streams in upper secondary education were not affected by this: no realistic problem solving was included in the math and science-oriented curriculum. The national examinations remained straightforward and traditional, so these-high level-students could be prepared for higher education without any skills to invent new strategies for new types of problems.

For the students who were preparing for the humanities, a new curriculum was developed, the mathematics A curriculum (De Lange 1987), based upon realistic mathematics education (which will be discussed in the next section). It was introduced as a new curriculum subject in pre-university education (vwo) in The Netherlands in 1989. Since that year, in upper secondary school, two different types of mathematics curriculum were being taught, mathematics A and mathematics B. Mathematics B contained the mathematics needed for technical studies and studies in science and mathematics at university level, its core component is calculus. Mathematics A was meant for students who prepare for academic studies in social or economical sciences or other related subjects.

The purpose of developing the mathematics A curriculum was described as follows:

Mathematics A is intended for students who will have little further education in mathematics in their academic studies, but who must be able to use mathematics as an instrument to a certain extent. In particular, we have in mind those who have to prepare themselves for the fact that subjects outside the traditional sciences are more frequently being approached with the use of mathematics.

This means that students must learn to be able to assess the value of a mathematically tinted presentation in their education. To do this they must become familiar with the current mathematical use of language, with formulations in formula language, and with divergent forms of mathematical representation. Furthermore, they must learn to work with mathematical models and be able to assess the relevance of these models.

(Werkgroep van advies voor de herverkaveling eindexamenprogramma's Wiskunde I en Wiskunde II vwo 2005, p. 19)

In mathematics $\mathrm{A}$, the emphasis lay more on applications of mathematics and on mathematical modelling than on 'pure' and abstract mathematics, and also more on the processes needed to come to an answer than on the answer itself (the product). In its initial years, modelling and problem solving were at the heart of this subject. The research along the introduction of mathematics A (De Lange 1987) showed examples of real world problem solving, and of the use of mathematics to solve real world problems. It also revealed that problem solving lends itself excellently to group work, which brought new problems and possibilities to the fore, especially in the area of assessment. The research hinted already at a fact that is now almost taken for granted, as the outcomes of PISA 2003 prove: inter-subjective scoring can be very reliable and fair (OECD 2005, p. 227).

Maybe because of the successful introduction of this new type of mathematics, problem solving in The Netherlands since that time seems to be identified with solving real world problems using mathematics. Even in the 'harder' and more scientifically oriented curricula, problem solving was introduced 'in context'. Inside-mathematics problem solving seems not to have caught on in The Netherlands, at least not on a large scale.

In the ongoing discussion in The Netherlands, there is a lot of confusion about the true meaning of problem solving in relation to the theory of Realistic Mathematics Education. So let us now address this relationship.

\subsection{Realistic mathematics education and problem solving}

In the aforementioned study (De Lange 1987), the real world problems were used for problem solving in two ways. First, according to the theory of Realistic Mathematics Education, the real world is a source or starting point for the development of mathematical concepts (Freudenthal 1991). Well chosen contextual problems offer 
opportunities for the students to develop informal, highly context-specific solution strategies, and are used to support mathematical concept building (Gravemeijer and Doorman 1999). In this phase, the criterion of potential for mathematical concept development dominates the criterion of authenticity. In fact, the context may even be rather unrealistic or within mathematics, if concept development requires it. However, the contextual problem must be experienced as a real problem by the students.

The second role of the real world is a little different. The real world is used as the domain in which we can use our mathematical concepts in the way we wish. The real world now has to be truly authentic in order to let the highly appreciated process of mathematization take full bloom. The idea behind this application phase of the learning process is twofold: to reinforce the concepts already developed, and to engage in problem solving activities: develop and deepen strategies.

If we reflect critically on the developments of the past decades we distinguish three factors that made the implementation of problem solving only a limited success in Dutch mathematics education. First, it became increasingly difficult to make quality assessments for mathematics A. The examinations became more and more predictable, so part of the real problem-solving component was lost. Second, many people translated the ideas behind mathematics A in a somewhat restricted way: the conceptual mathematization part and the applied mathematization part were confused, resulting in examination standards of long stories in which students had to apply little mathematics. Third, the level of authenticity went down with the increased use and popularity of 'applied problem solving'.

\subsection{Today's problem solving practice}

To summarize the state of the art in Dutch mathematics education, we notice that students in upper secondary education are not often confronted with inside-mathematical problems for which no known strategy is available. This may be the reason for the modest scores of The Netherlands in the mathematics Olympiads. Another matter for concern is the lack of problem solving activities in primary education. The focus here is on word problems and eventually on solving real world problems. Solving insidemathematics problems is merely absent.

To assess the state of affairs concerning problem solving in Dutch mathematics education, we will now first look at the PISA-2003 results. Next, we will discuss a study on problem solving in primary education. Then, a problem solving competition for upper secondary education will be presented. The paper continues with remarks on the opportunities that the integration of technology offers for problem solving, and ends with a conclusion.

\section{Recent PISA-results}

\subsection{PISA-2003}

In the 2003 version of the programme for international student assessment (PISA) study, mathematics was the main focus. Problem solving was an additional domain in PISA-2003. The idea behind this domain, usually not taught as a separate subject, was to test general problemsolving skills of students aged 15-16. Being able to apply problem-solving skills in a variety of domains is an important educational target in many countries and, as indicated by the OECD (2003), these competencies are the foundation of effective participation in society and development of talents in personal and professional life.

In order to solve these larger problem-solving tasks, students must understand and interpret the available information, recognize important elements that are represented and make connections to the real world situation. They must be able to reason and communicate their arguments in writing. The solution is not obvious and the skills needed usually do not belong to a single educational domain such as mathematics or science.

Within the domain of mathematics education, problem solving is seen as solving problems for which standard solution strategies are not yet available. In general, this means the investigation of a larger problem. Often, these problems in PISA-2003 are situated in a more or less realistic situation. To solve these, the student first has to 'translate' the information and to create a (simplified) mathematical model of the situation. After the problem is solved within this mathematical model, the results are compared to the real life problem situation. This might result in rejecting (some of) the results, rounding the answers according to the situation or to adjusting the mathematical model (De Lange 2006).

There is a strong connection between mathematics as an educational subject in The Netherlands and problem solving as defined by the PISA programme. Therefore, research from the Dutch national test institute Cito and the Freudenthal Institute included the PISA problem-solving domain in a further analysis of the Dutch national mathematics results of the PISA-2003 study (Dekker et al. 2006). We now present some of the findings of this study.

\subsection{Problem solving and mathematical literacy} in the national study

Score points for both mathematical literacy and problem solving literacy have a mean of 500 and a standard deviation of 100. This enables a comparison between the results in both domains. In the 2003 study, the Dutch mean score for mathematical literacy was 538 (place 4 on the inter- 
national list) and the mean score for problem solving was 520 (place 12 on the international list). Figure 1 shows that the difference between the two scores was the largest in The Netherlands as compared to all other participating countries; students in The Netherlands performed better in the domain of mathematics than in problem solving (Gille et al. 2004).

The international PISA report (OECD 2004a) claims that the relatively high score of mathematical literacy as compared to the problem solving results indicate that mathematics education in The Netherlands, as measured by PISA, is very effective. However, one could also argue that problem-solving skills are lagging behind. Furthermore, the researchers indicate that in no other country, apart from The Netherlands, mathematics education is as aligned with the competencies measured by the PISA study. Another explanation is that the PISA problem solving tasks emphasize general analytical argumentation skills without building upon mathematical skills. Could Dutch students be lacking these general skills? The research could neither prove nor refute this.

Fig. 1 Differences between mathematical literacy and problem solving. Source: OECD 2004b, p. 54
When looking at student work on the mathematics assignments, the researchers found that Dutch students, when compared to their peers in neighbouring countries (Belgium Flanders and Germany), were less persistent when working at large tasks which took a lot of time and energy to complete. This was not caused by a lack of confidence; students in The Netherlands did not often skip tasks, but almost always at least started the solution process. However, they gave up sooner, especially when dealing with extensive and challenging tasks. The student work on the problem-solving test was not analysed in this study, but it may be expected that the same phenomenon occurred there.

\subsection{Are Dutch students mathematically literate?}

As shown earlier, Dutch results were satisfactory when compared to other OECD countries. But The Netherlands is a highly developed industrial country and demands are high for labourers in almost all professions. Which level of mathematical literacy should this country strive for? The

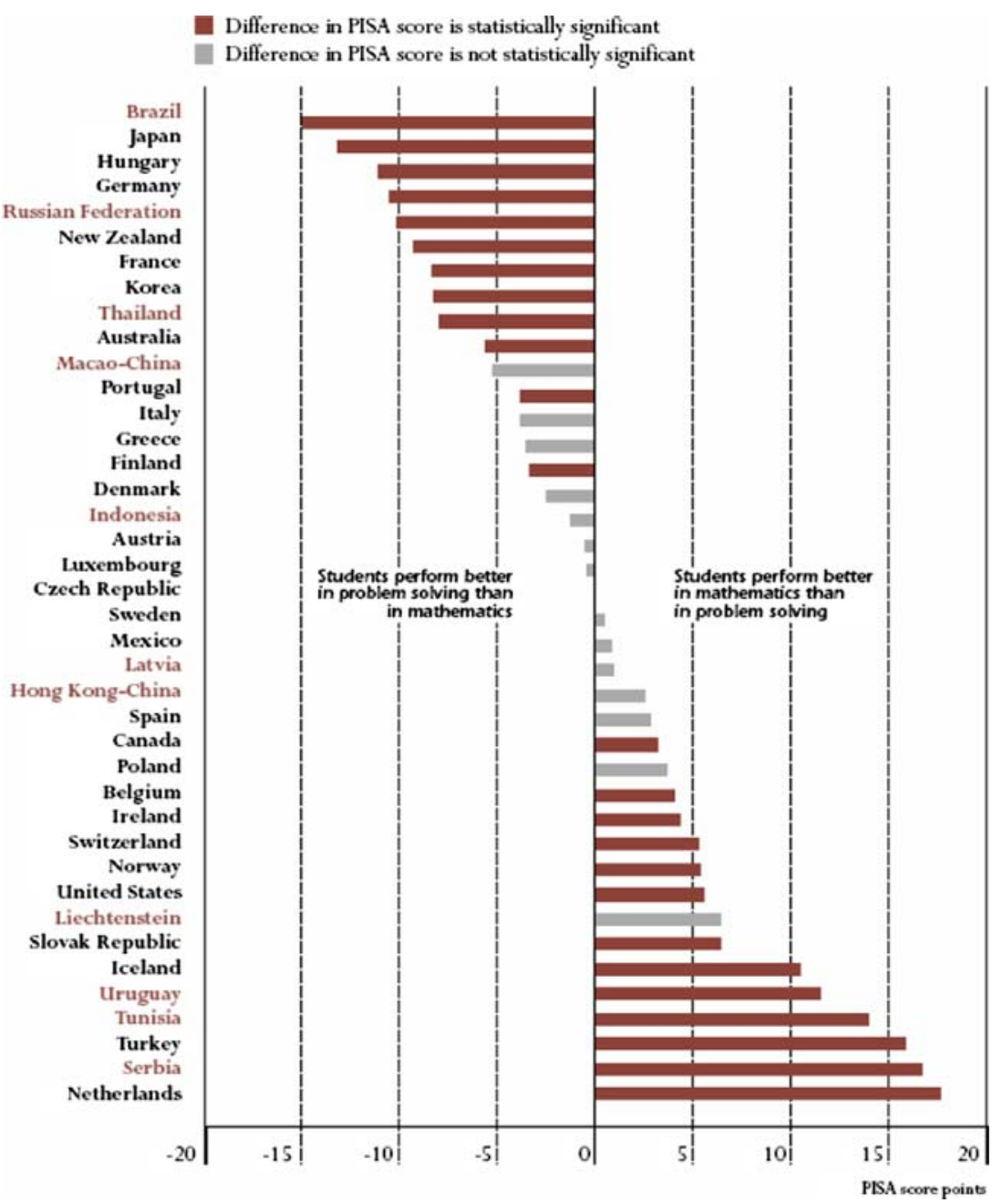


PISA study discerns six levels of mathematical literacy. Level 1 starts at a score of 358 and ends with 420, level 2 has scores 420-482 and level 3, which contains the overall mean score of 500, runs from 482-544. Level 4 scores are within the range of 544-606, level 5 from 606-668 and at level 6 scores are 668 and higher. Students working at mathematical literacy level 4 can

....work effectively with explicit models for complex concrete situations that may involve constraints or call for making assumptions. They can select and integrate different representations, including symbolic ones, linking them directly to aspects of realworld situations. Students at this level can utilize well-developed skills and reason flexibly, with some insight, in these contexts. They can construct and communicate explanations and arguments based on their interpretations, arguments and actions.

The mean score for Dutch students preparing for university (vwo) was 639 in the PISA 2003 study. Students preparing for vocational studies at a higher level (e.g. to become a high school teacher or highly skilled laboratory assistant) scored 594. However, about $60 \%$ of the Dutch students at age 15 prepare for vocational education at a medium or low level (vmbo) and most of them do not have scores at level 4 or higher as we would expect them to have. When looking at the content of the PISA mathematical literacy problems, these seem more suited for vmbo students and less for havo or vwo students.

There are large differences between the countries taking part in the study and this means that very weak students in some countries must be able to answer at least some of the questions. And so the Dutch results may seem satisfactory as compared to other countries, by our own standards they do not seem good enough and much is left to be desired. Furthermore, the largest contribution to the relatively high score in mathematical literacy in The Netherlands came from the Reproduction cluster and not from the clusters Connections and Reflection.

Providing sound arguments is a difficult task for all students, but Dutch students have been trained in doing so during their school career. Moreover, for lower achieving students the language aspect is an important issue, for both passive and active use of language. The result of the Dutch analysis of the PISA 2003 study led to some recommendations which are, not surprisingly, different for different groups of Dutch students. For students at upper secondary level, more emphasis should be placed on formal and abstract mathematics.

For students in the lower ability groups (vmbo-level) reading and interpreting skills need attention in order to be better prepared for solving problems that are challenging to them. This recommendation was made since we feel it is unacceptable that so many students aged 15 are not mathematically literate at the PISA scale of level 4.

To summarize this brief review of the Dutch PISA 2003 results on mathematical literacy and problem solving, the most surprising result is that the problem-solving scores are lagging behind. As learning to solve problems starts at an early age, we now first consider a study on problem solving in primary education.

\section{Problem solving in primary education}

Although the reform in mathematics towards Realistic Mathematics Education resulted in a new generation of primary school textbook series, problem solving, in the meaning of solving non-routine mathematical problems, was hardly given any attention in these textbooks. At most the reform brought-to a certain degree-more complex realistic problems in which the children had to figure out, for instance, which of the several journal subscriptions is cheaper and what it costs to organize a birthday party. Puzzle-like problems, in which it is not directly clear from the beginning how to start with solving them, are scarcely found in the new textbooks. At best, one can come across these problems in additional materials for high achievers.

As in the textbooks, non-routine problems are also not included in the Cito test, taken by $90 \%$ of the sixth-graders at the end of primary school (Cito is the national institute for assessing educational progress). This test, through which children get access to the higher levels of secondary school, only consists of routine problems in a multiplechoice format.

The lack of non-routine problems in textbooks and the Cito test make that not much attention is paid to problem solving in primary school. Teachers do not offer children an environment in which they can develop problem-solving skills and the attitude that is necessary for coping with nonroutine problems. A mitigating circumstance that is often mentioned is that problem solving is something that is only attainable by the best students and that these bright students can help themselves and do not need much help for learning to solve non-routine problems. However, this assumption is in contrast with the results that were found when in 2004 high-achieving fourth-graders in twenty schools were given a test on problem solving (see Van den Heuvel-Panhuizen and Bodin-Baarends 2004).

For all of us who thought that we as mathematics developers and researchers did our job quite well and contributed to bringing our students into the higher ranks of international mathematics achievement, the results of this study came as a rude awakening. In the next section, we will give more details about the study. 
4.1 A study on problem solving by high achievers in grade 4

To begin with, it is quite telling that there was an external reason for doing this study. The direct cause was a request from Peter Pool and John Trelfall from the Assessment and Evaluation Unit, School of Education, University of Leeds to investigate how Dutch high-achieving fourth-graders will perform problem-solving tasks that have been developed for the World Class Tests. In total, 15 problems were chosen which, for the number domain and the operations to be carried out, were more or less covered by the mathematics curriculum these Dutch students had dealt with in grade 4. However, the nature of the problems was somewhat special for the Dutch students. Most of the tasks were puzzle-like problems, such as number riddles. Students do not encounter this kind of problem that often in textbook series and tests in The Netherlands. The 15 problems were put in a test booklet with every problem presented on a separate page. The children were free to use the whole page as scrap paper. For some problems there was an explicit request to show how they solved them.

In total, 152 high achieving students in grade 4 (910 year olds) took the test. The students belonged to the top $20 \%$ ability range in mathematics. They were selected by their teachers on the basis of their mathematics score. In most cases this was the students' score on the Cito Student Monitoring Test.

\subsubsection{Some revealing results}

The analysis of the student responses in the test booklets showed that quite a number of the children did not make use of the work space when solving the problems. They did not have any other scrap paper available; this means that they worked on the problems without writing anything down. This is remarkable, especially for problems that involve a lot of data or where you can find a solution by systematically trying out several options. For these problems, it is often practical to make notes and write down intermediate answers. Figure 2 shows an example of such a problem.

Table 1 shows the results on this item. Clearly, the problem was fairly difficult for the Dutch high-achieving fourth-graders involved in the study. Only 39 students, a quarter of the total group (25.7\%), found the right number. The students in the United Kingdom did slightly better on this problem. Of the 184, year 4-5 students (8.5-9.5 years) who did this problem and who belonged to the 15-20\% best students in mathematics, $34.2 \%$ came up with the correct answer (Peter Pool and John Trelfall, personal communication).

Furthermore, Table 1 reveals that 93 of the Dutch children, almost two-thirds of the total, did not make any

\section{Find the number}

It is smaller than 100 .

If you divide it by 7 , there is no remainder.

If you divide it by 3 , the remainder is 2 .

If you divide it by 5 , the remainder is 1 .

Fig. 2 Problem: Find the number

Table 1 The results from high achievers in grade 4

\begin{tabular}{llll}
\hline & \multicolumn{3}{l}{ Results for the problem 'Find the number' } \\
\cline { 2 - 4 } & $\begin{array}{l}\text { Did not use } \\
\text { scrap paper }\end{array}$ & $\begin{array}{l}\text { Did use } \\
\text { scrap paper }\end{array}$ & $\begin{array}{l}\text { Total number } \\
\text { of students }\end{array}$ \\
\hline Correct answer & 19 & 20 & 39 \\
$\begin{array}{l}\text { Wrong answer } \\
\begin{array}{c}\text { Total number } \\
\text { of students }\end{array}\end{array}$ & 93 & 39 & 113 \\
\hline
\end{tabular}

use of the scrap paper. Even out of the 39 students who came up with the correct answer, 19 did not use the scrap paper. Since high achievers in mathematics were involved in this study, it is not really surprising that roughly half the children found the right answer mentally. Although this problem needs much calculation work, the difficulty does not lie so much in the knowledge of the tables of multiplication that is required. Bright students in grade 4 mostly know their tables. What it comes down to in this problem is the ability to take into account a number of different criteria at once. The result that gives more cause for concern is that 74 of the 113 children who did not find the right number did not write anything down.

The after-test interviews that were held with a selection of the students disclosed that the difficulties with this problem were not related to understanding the question. The children clearly understood the intention of the problem. Although the calculation itself did not always go as smoothly as one would expect in this group of students, that also was not the core of their problem. The study made it clear that the weakness of these good students lay in a different area, namely in not trying and not being able to keep up a particular approach. Moreover, this attitude might be strengthened by the fact that the children apparently were not used to writing something down to support their thought process.

In reviewing all the students' responses and the experiences from the interviews, three tendencies were found: many students did not write anything down, many students did even not start, and if they started quite a number showed lack of persistence. 
The tendency not to write anything down. This tendency raised many questions, but the study also revealed some ideas of how to explain this behaviour. For example, children (and teachers) might think that it is better not to use the paper, because they think that solving the problems mentally is a higher level of mathematics. The trend might also have to do with the fact that bright students hardly use (scrap) paper when they do their assignments in regular mathematics classes. A very different aspect that might play a part is that the children do not write anything down because they feel that you should not 'make a mess' in a test. They learned from their teachers that it is important to work tidily.

The tendency not to start with the problem. The fact that the majority of the children who could not solve this problem did not try anything on paper either, is also significant. Except that the trend to not even start could result from the abovementioned refusal to write down anything in solving mathematics problems, another possible explanation could be that the children have not learned to use notes and organize data as a support for the solution process. In the case of this problem, one could think of listing the numbers that qualify according to a certain rule and then strike out the numbers that do not conform. Trying things out might break through the all or nothing atmosphere that now often prevails.

The tendency not to persist when attempting to solve the problem. A quite alarming experience in this study was that high-achieving students gave up after trying a few numbers. A possible explanation for this reaction may be that good students can find it difficult to persevere because they do not often come across problems that require profound mathematical inquiry. They usually do not have to think very long about the problems they normally encounter.

\subsection{Some final remarks on problem solving in primary education}

As was mentioned before, non-routine problem solving has a marginal place in the present Dutch mathematics curriculum in primary school. We believe that this should change and hope that the start that is given for this in the TAL learning-teaching trajectory for calculation with whole numbers in primary school will have an effect in teaching practice (Van den Heuvel-Panhuizen 2001). A complicating factor here is that up to now there has not been much support from textbooks series and the Cito test at the end of primary school. Both still stay far away from non-routine problem solving.

However, an interesting initiative to enhance problemsolving skills in primary education is the recently established Great Arithmetic Day. On this day, that is organized by the Freudenthal Institute, thousands of primary students (and their teachers) are engaged in problem solving. More research is necessary to see whether this extra-curricular activity can introduce more problem solving to the Dutch primary school curriculum.

After this short impression of the state of affairs concerning problem solving in Dutch primary education, we now turn to secondary education.

\section{Problem solving at secondary level}

As in primary education, problem solving in secondary mathematics education has only a marginal position. In the introduction to this paper, it has already been pointed out that even an application and modelling-oriented curriculum like the one for mathematics A tends to standardize problem-solving tasks into routine assignments. The national examination does not encourage paying much attention to problem solving skills. Textbooks usually do not address problem solving as a result of examination demands, designing teacher and student proof activities, and the time need for designing problem solving activities. An exception is the textbook series 'Wiskundelijn' (Bos et al. 1990), which contained so-called Systematic Problem Approach items. Such an 'SPA' explicitly aimed at the development of heuristics for dealing with open problems in the sense of Van Streun (1991).

Important initiatives for enhancing problem solving activities in upper secondary education are the Mathematics A-lympiad and the Mathematics B-day competitions. As we consider this to be types of competition which are exemplary to problem solving, an example of the first is discussed in more detail.

\section{Mathematics A-lympiad: an experimental garden for problem solving}

It seems obvious that problem solving should be an inherent part of the mathematics A curriculum. In the educational practice of mathematics $\mathrm{A}$, however, less and less attention was given to really open ended problems that address higher order thinking goals, problem solving and modelling. This is mainly due to the fact that Mathematics A is assessed in a central, written, individual, final examination. The design of examination tasks that do justice to the purpose of the mathematics A curriculum turned out to be difficult. The examination questions, although presented in a seemingly realistic context, seldom asked for modelling or problem solving on a serious level. If these skills are not needed for the examinations, one cannot expect a great deal of attention to be paid to them during education. And so the circle is closed: 'poor' final exams bring about 'poor' education. 
To break this circle, the Mathematics A-lympiad was established outside the examination system. Its intentions were to design a 'task' that encompasses the original objectives of mathematics A and that asks for teamwork as well. As an extra motivating factor this task would be presented to students as a team competition.

In the announcement that is sent to all secondary schools with pre-university education, the competition is described as follows:

The competition is intended for students in grades 11 and 12 (age 16-18) who are taking mathematics A as a subject. It involves tackling a challenging problem as a team (three or four students). The competition consists of a qualifying preliminary round at the school and a final round at the weekend (Friday and Saturday) in a conference centre.

The open nature of the task implies that the teams have to forge the entire path from defining the problem, via strategy definition, solution and argumentation, through presenting the solution found. The result is a paper containing all of these aspects.

\subsection{The competition and school examination}

The Mathematics A-lympiad competition has been running since 1989. It consists of two sessions, a preliminary round in the schools and a final session in an external location. The competition has seen a growing number of participating schools in the first 10-12 years, though that number seems to have stabilized over the last couple of years with about 150 schools participating, with a total of about 1,500 teams. This means that every year about 6,000 Dutch pupils work in teams on an open ended authentic assignment for mathematics. An increasing number of foreign teams (from Denmark, Germany and the Dutch Antilles) participate in an international final round.

In the early years of the Mathematics A-lympiad, it was exceptional in mathematics education to call on skills such as problem solving, reading, writing, doing research, forming arguments, reasoning, critically reviewing mathematical models, mathematization, teamwork, planning: the full range of general and mathematical skills. With the Mathematics A-lympiad these skills have gained a set place in a large number of schools in The Netherlands. This type of mathematics is precisely the mathematics that many students will deal with later on in society: solving more complex problems in teams where technical tricks alone will not do. In the next paragraph we will present an example of student work on one of the assignments.
6.2 The diversity example-analysis of student work

An assignment in a final round was about bio-diversity. Various species of plants and animals are disappearing every day. The task for the student teams was to decide on criteria for determining which plants and animals are most important to save, if the goal is to keep species diversity large enough.

In the first three problems the teams had to familiarize themselves with the concept of bio-diversity. Then a relative value scale had to be developed for the genetic relationships of species. This value scale was to be used for determining which species it would be better to protect in order to keep diversity, from a genetic point of view, as great as possible. In brief: the teams had to develop a decision-making model. This model should then be used for making decisions on the preservation of species.

\subsubsection{The plants in the photos}

The assignment started as follows (see also Fig. 3).

'A number of photos of different combinations of plants (A, B, C and D) was given to a number of scientists who then ranked them according to decreasing diversity.'

Using this information the teams had to decide what factors were clearly seen as important for diversity. Teams were not asked to devise a function themselves that produces this ranking, but almost every team tried to do so. This was probably done to compare their own ideas with the assessment of the scientists. In general, there was little difference for the factors found by the teams. As most important criteria for determining the level of diversity were mentioned:

- the total number of plants;

- the number of species;

- an even distribution of the numbers per species.

The standard deviation of the numbers was calculated as a measure for this distribution. A smaller standard deviation was synonymous with better diversity. Some teams did not think that this was altogether correct as a photo with a few plants would be given a greater diversity than a photo with many plants in the same ratios. One team replaced the absolute numbers by percentages, as did a number of other teams (Fig. 4).

One team did not think this was correct and explained why, using a fictitious photo containing only one species. The standard deviation would then be zero and that would mean that it had the greatest diversity, even though in fact it has the minimum diversity. 
Fig. 3 Part of the diversity task

\begin{tabular}{|rrrrrrr|l|}
\hline & A & B & C & D & E & & \\
\cline { 2 - 6 } photo 1 & 40 & 10 & 20 & 5 & 5 & & photo 3 \\
photo 2 & 40 & 20 & - & 25 & 30 & photo 2 & decreasing \\
photo 3 & 40 & 20 & 10 & 25 & 30 & photo 4 & diversity \\
photo 4 & 40 & 30 & 10 & - & 20 & photo 1 & \\
\hline
\end{tabular}

Another team concluded that according to the above method the diversity was greatest when all plants occurred in equal quantities. However, nature is better served by equilibrium than by equal quantities. And in equilibrium:

'... for example, very many more bacteria are needed than elephants.'

A better factor for determining the level of diversity is how much the number of each species in a photo differs from the average number of this species (in all photos). The thinking behind this was that the ecological equilibrium will not be far from the average numbers. This method meant that the photos with plants in the ratio of: 40:20:10:13.75:21.25 had the greatest diversity. When the ratios were equal, a higher diversity would be allocated to the photo with the greatest number of plants.

A different team compared the numbers of plants (see Fig. 3) with the calculated averages. Checking this approach by using the plants on the photos meant that photo 3 had the greatest diversity, as it was the one that best corresponded to the desired averages. Next is photo 2 as one species was missing there. Then photo 4 because species $\mathrm{D}$ had died out there and it was a species that occurred more on average than species $\mathrm{C}$, which was absent in photo 2. Photo 1 was the last due to its large differences from the averages, especially for species D and $\mathrm{E}$. This order corresponded to the order established by the experts.

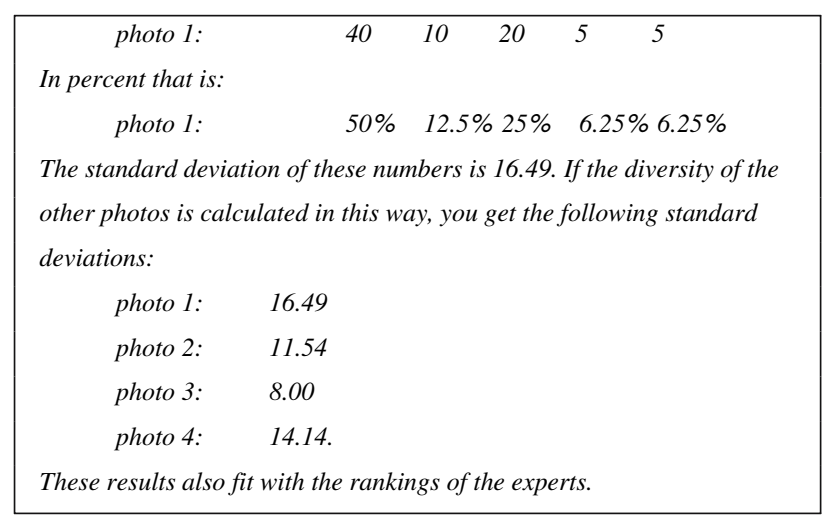

Fig. 4 One team's result

\subsubsection{Genetic variation}

In the second part of the assignment the teams were asked to determine which species it would be best to protect from the point of view of genetic diversity, by using a genealogical tree of genetic relationships.

The teams were asked to develop a value scale which, together with the genealogical tree, could be used to determine which species had to be protected and which could be allowed to disappear if there was no alternative. In the genealogical tree presented as an example in the assignment (Fig. 5), it is specified for two combinations of species which combination it would be better to protect from the point of view of genetic variation.

Problems can arise here with regard to the term 'genetic variation' as it can be defined in different ways. In general, two approaches are recognized in the students' work. The first approach uses the relationship between a species and the original species. In this approach, the defined objective is to preserve the original genetic material as much as possible. Species that have branched off more often are further away from the original species and will thus contain less of the original material. With each division, the teams assumed that a certain percentage of the material was transferred into the new species. The teams that used this approach conceded that these percentages were based on their imagination. Generally the teams used a division in equal parts, as is shown in Fig. 6.

Some teams who wanted to preserve the species that were closest to the original species had rather strange theories. The preservation of these species would have the advantage that 'as many genes as possible' would be preserved. Species that were further away from this original species contained 'fewer genes'. It was also believed that by maintaining the original material the species that disappear could occur again more easily.

The second approach examines how the different species are mutually related. This can be done by counting the nodes from one species to the next.

You go through the tree from one species to the next and count along the way the number of places where new species occur. This number is called the distance between two species. These distances were set out by the teams in a matrix and the columns were then summed. These totals were then a measure of relatedness. 


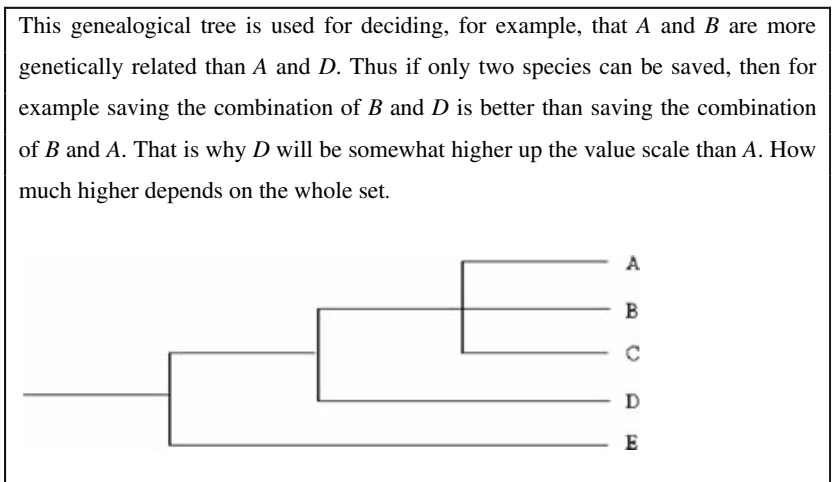

Fig. 5 Continuation of the task

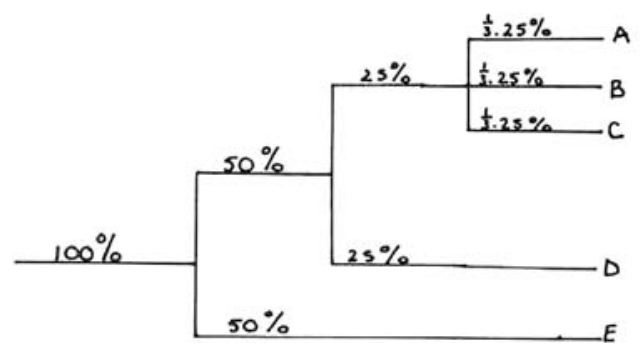

$8 \$ \%$ $8 \% \%$ $8 \%$

$50 \%$

Fig. 6 Tree with probabilities

Figure 7 shows this matrix and the accompanying tree, made by one of the teams. The species with the smallest total distance is the one most related to the other species and can, if necessary, be the one most easily dispensed with. When this species is left out, a new tree can be made and the process is repeated. If, as a result of selection, at a node only one of the species had remained, almost all of the teams left this node out as if it never existed. This move was never justified but is indeed consistent when you consider all of the species that have died out whose existence is unknown to us. It is striking that none of the teams thought of looking at the minimum and maximum distances instead of the sum of the distances. After all, a minimum distance means a close relationship between the two species and a maximum distance means a distant relationship. With two species that are closely related, it is less serious if one of them dies out, at least according to the exercise.

The teams now had to adapt their value scale in such a way that it was not possible that one species did obtain an extreme score. In other words: the system had to give somewhat 'flattened' results. A number of teams combined the approaches mentioned before. The one group added up the values from the value scale, another multiplied them. For example, the distances were multiplied by the percentages. Logarithmic and exponential functions were also used to bring the values closer together. None of the teams examined this problem critically. One team stated that

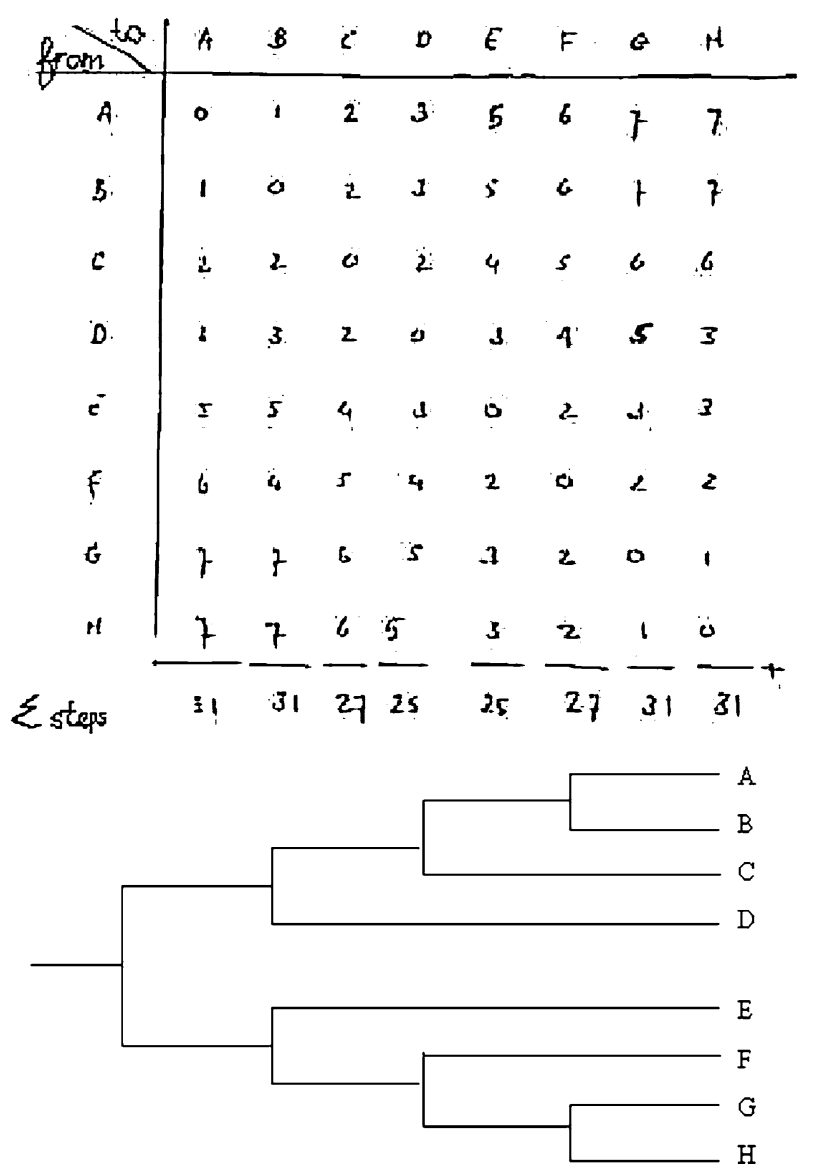

Fig. 7 Matrix and tree

flattening the system leads to a higher reliability. However, they did not explain.

\subsubsection{Comments}

Some participating teams commented on the task in interesting ways. For example, a number of teams criticized the approach in part 2 where genetic variation was the central issue. According to these teams, there are more important arguments for prioritizing the preservation of certain species, i.e. ecological. As an example, take a family of species that acts as prey, prey-predator, and predator within an ecological system.

Some finalists thought it was more important for stable species (with fewer divisions) to be preserved. On the other hand it can be argued that it might be better to protect quickly developing branches as new genetic variations will occur more easily through them.

The task went on with a question on including a time component to address the genetic evolution in time. For reasons of space, this extension is not described here; we refer to De Haan and Wijers (2000) for a more extensive description of the assignment. 


\subsubsection{Concluding the example}

The search for an acceptable value scale by the teams was often a wild search for appropriate formulae. Teams often arbitrarily multiplied, divided, added and subtracted. The underlying arguments were often forgotten in the process. It was for instance stated that a certain parameter was important, but was not yet included in the scale, without saying why they chose to include this specific parameter in this specific way. This makes the allocation of values arbitrary.

This can be seen as a criticism of the assignment or of the pupils, but it is more a criticism of the process of allocating values. Furthermore, there was lack of clarity with the terms. Where for example is the separation between a breed and a species within evolution theory? Is this part of the assignment about making a choice between different species of finches or the choice between a dog, a cat and a squirrel?

The reader will notice that nowhere in the assignment it was said that a formula had to be devised, but rather a 'system'. Why was it that almost all teams searched so frenetically for a formula? Could it be caused by the use of terms such as 'value scale' and 'tree'? It is not easy and often even impossible to convert non-mathematical considerations into formulae. It is often better to simply reason them out. After all, one does not know how the different considerations are linked together and how they have to be included, and whether there are still unknown, more important factors.

'Chance of survival' indeed seems to be a number, but nobody knows how to calculate it. It is more a probability derived from small talk than from theory or experiments. That's why one of the teams stated:

We have to throw all the criteria into a large basket and determine the value of each criterion. This presents a considerable problem. Every individual weighs every criterion differently. You might think that the economic aspect is important, but so also is the social aspect. You can proceed purely rationally, but also emotionally! In order to come to a reasonably objective opinion you must present your criteria to a cross-section of society.

\subsection{Influence of recent educational reform}

Since 1998, upper secondary education in The Netherlands has been restructured. A part of this reform is the growing attention that is paid to general skills embedded in several subjects. Larger, more complex open-ended tasks, which focus on general skills as well as on subject-related skills became a compulsory part of the school exam for every subject. These skills are highly reminiscent of those mentioned as objectives for mathematics A in 1980. It is pre- cisely because these skills will be assessed in the school exams, that the interest in teaching and practicing higher order skills has been revived. The assignments of the Mathematics A-lympiad turned out to be perfect examples of this kind of tasks and since 1998 its assignment is used as part of the school examination in many schools. A similar competition for Mathematics B, the Mathematics B-day, is used in the same way and with equal enthusiasm. The experiences with the B-day show that problem solving tasks that are appropriate for team competitions can be designed within the domains of pure mathematics and mathematical applications in exact sciences as well.

From an organizational point of view, participating in the Mathematics A-lympiad and B-day is very convenient for the school: the assignment is provided by a committee of experts; in one day, teams can produce a paper; students are deprived of the possibility of obtaining 'expert knowledge' from elsewhere, since everyone works for the entire day on the same task.

There is, however, also a downside to this development. As doing open-ended assignments, writing papers and essays as well as working in teams became a regular aspect of the mathematics lessons - and of other curriculum subjects- the initial motive for the Mathematics A-lympiad-to offer 'a completely different type of assignment'-became less important. This might have had a slightly negative effect on the quality of the student work for the Mathematics Alympiad assignments. Nowadays, the mathematics is often used on a more basic level, without the extra considerations and argumentations that characterize real problem solving. Other factors than getting used to this type of tasks play an important role in the quality as well, the most obvious being the recent reduction in math lessons ('teaching time') by about 50\% in The Netherlands. Nevertheless, the design of the assignments and the evaluation of student work during the finals remain an inspiring experimental garden for investigating possibilities for problem solving in mathematics education.

\section{New tools create new possibilities}

As a final perspective on problem solving, we consider the use of technological tools. New technological tools create new possibilities for problem solving in mathematics. These possibilities, as well as the difficulties, are now illustrated for the case of the integration of the graphics calculator.

As in many other countries, the graphics calculator was introduced in the Dutch mathematics curriculum during the nineties of the previous century. An important didactical motivation for integration in the curriculum, as well as in the national examination, is the way this tool supports 
explorative activities and problem solving abilities (Drijvers and Doorman 1996). Tools like the graphics calculator provide a new and rich variety in possible problem solving strategies. Even weaker students appear to be supported by this (Streun et al. 2000).

The integration of the graphics calculator also fostered new mathematical practices that would not be possible without technological tools. We sum up some of the most remarkable changes:

- Thanks to its direct feedback, the graphics calculator offers opportunities for exploratory activities. Even during the initial phase of familiarization, a problem can often already be investigated graphically. Inventory and classification activities can lead to discoveries which then, through reflection and generalization, result in interesting mathematical theorems. This contrasts with the traditional method, in which definitions and theorems are stated at the beginning of the learning path in the expectation that insight will be acquired through repeated application.

- One can quickly and effectively follow the results of variation in the problem. The influence of a given parameter in the formula can easily be visualized by using graphics. This enables users to continually alter their frame of reference from global to local and vice versa.

- Due to the use of technological tools, the repertoire of techniques and skills a student must master will remarkably change. Freehand drawing of a graph based on a strictly prescribed analysis of functions - a much practiced skill in the past-will hardly matter. On the other hand, skills such as estimating numerical values, reading graphs, setting viewing windows and improving approximations increase in significance. A shift in emphasis occurred away from traditional techniques and towards a more flexible solution procedure, in which a critical attitude is developed with respect to numerical results.

The following example illustrates the ways in which students made use of the graphics calculator's potential for explorative activities. In Fig. 8, two coins lie next to one another. The coin on the left is fixed. P is the point on the edge of the coin on the right where it touches the coin on the left. The coin on the right is now going to roll around the edge of the coin on the left without sliding. The problem is: what is the locus of point P?

The first questions in the task contained a concrete orientation, the choice of an appropriate coordinate system and the constructing of the motion equations. So far, questions with straightforward solution strategies for these students. Then the students draw the curve with their graphics calculator, creating a cardioid-shaped image. The distance of the moving point to the centre of the coin can

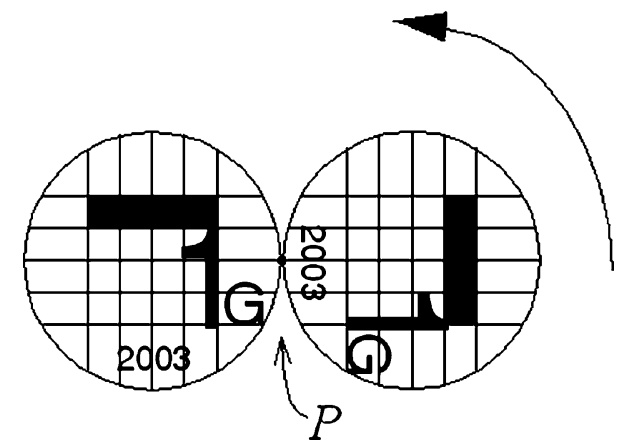

Fig. 8 The problem situation with the rotating coin

be changed. This can be generalized and the students can investigate a variety of cases. This activity is new to them, and they do not have standard solution strategies at hand. They are free to classify the graphs they find as they choose. The focus is on their investigational activities.

The graphics calculator immediately revealed any error by drawing an 'impossible' curve. This led, on the whole, to an improvement in the initial motion equations. For instance, a number of students entered the following:

$x(t)=2 \cos t-1+\cos (2 t)$

$y(t)=2 \sin t+\sin (2 t)$

The drawing in Fig. 9 revealed what was wrong.

This could now be improved! The students then entered:

$x(t)=2 \cos t-1+\cos (2 t+\pi)$

$y(t)=2 \sin t+\sin (2 t+\pi)$

Ruthven (1992) uses the expression 'trial and improve' for such problem solving skills with a graphics calculator at hand. The matter of varying the distance between $\mathrm{P}$ and the centre of the rolling coin could also be dealt with. Students create graphs as shown in Fig. 10.

Interesting drawings result from these so-called Pascal curves. During the last five minutes of the lesson, the results of classifications of the curves were listed on the board.

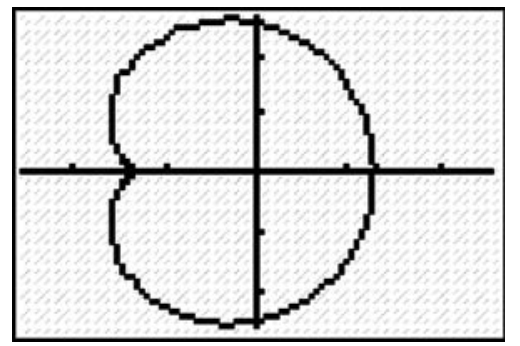

Fig. 9 The cardioid on the screen of a graphics calculator 


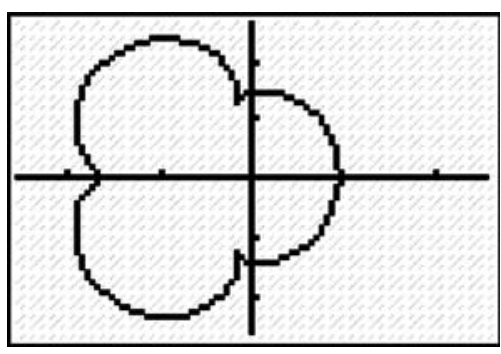

Fig. 10 Shamrock-shaped curve

\begin{tabular}{ll}
\hline$a$ & Shape \\
\hline 0 & Circle \\
1 & Cardioid \\
$0<a<1$ & 'dent' \\
$a>1$ & Loop \\
\hline
\end{tabular}

One student comments on the 'dent': "When $a$ is small, the dent is also small, and when $a$ gets bigger, the dent grows too."

Where the loop is concerned, the teacher asks: "Does it matter how much greater $a$ is than 1 ?"

Student: "When $a$ is close to 1, it's small; if $a$ is big, it's big."

Teacher: "So does the small one ever catch up with the big one?"

Student: "No, they'll overlap, they'll get close together."

The students watched the curves being created in a dynamic manner. The graphs became a starting point for further study, rather than the static end product of a vast ritual of investigation into intersections of the axes, horizontal and vertical tangents, etc. The graphics calculator is an excellent aid here. The students 'saw' the point on the plane shift and the speed of the movement became visible. The parametric equations that describe the movements on the plane really came to life this way.

The user can see how a graph (or a curve or a group of graphs) is created. When the picture is finished, TRACE offers the opportunity to follow the graph point by point and read the changing coordinates on the screen. The graphics calculator's direct feedback encourages the students to reflect upon what they have done. This alternation between experimentation and reflection is an important aspect of problem solving and concept development.

As a consequence, the graphics calculator supports exploratory activities. The students arrive at a classification that they themselves have developed through their own experience. The potential of the technological tool evidently stimulates many students to engage in informative explor- atory activities. The mathematical level of the result, however, tends to be rather varied. While such exploration can lead to excellent discoveries and insights, the results are at times disappointing. This has to do, on the one hand, with the fact that drawing conclusions from investigative activities places heavy demands on the students. Moreover, students have to learn to deal with open problems, to appropriate new tools and to develop an investigative attitude.

In addition to the aforementioned study on the opportunities that the graphics calculator offers to mathematics education, recent research projects at the Freudenthal Institute focus on tool-use in mathematics education and concentrate on computer minitools (Bakker 2004, Doorman 2005, Drijvers et al. 2007) as well as on computer algebra (Drijvers 2003).

To summarize the findings, we notice that the dynamics, the direct feedback, and the possibilities to deal with complex situations and to investigate many cases offer new opportunities for problem solving activities in mathematics education. The skills a student is expected to master are different from those required in traditional situations. We conjectured that the importance of mastering routine operations would decline and the necessity for developing a flexible attitude for working with tools would increase. Still, like the experiences with problem solving in the mathematics A curriculum, the difficulty for teachers and task designers is to avoid problemsolving tasks becoming routinized. If the students after their work on the previous example on the cardioid would encounter a task concerning the cycloid, their approach would be much more standardized.

\section{Conclusion}

If we look back at recent developments in mathematics education in The Netherlands, some remarkable observations can be made. While serious attempts have been made to implement a problem oriented curriculum, based on principles of realistic mathematics education with room for modelling and with integrated use of technology, we notice that this has been successful in educational practice only to a limited extent. The main difficulties encountered first involve the national examination, which strongly drives educational practice, but by its structure does not allow for real problem solving activities. A second obstacle is formed by the textbook series, which are not very open to problem solving and do not address its learning.

An important challenge is the design of good problem solving tasks that are original, non-routine and new to the students. Experiences with the Mathematics A-lympiad and the Mathematics B-day suggest that such tasks best can be developed in a team of educational designers and teachers. This is a non-trivial process. 
To overcome the difficulties, some measures should be taken - and to a certain extent are already in progress. First, we recommend textbook series to pay explicit attention to problem solving skills and heuristics. Second, schools should take the opportunity that school assessment provides for problem solving activities. National initiatives such as Mathematics A-lympiad and the Mathematics B-day offer inspiring opportunities to do so. Teacher networks for designing problem solving tasks can be fruitful, as might be an exchange through a virtual community. Third, we recommend that teachers and textbook authors exploit the benefits of technological tools for the purpose of problem solving. Through technology, new mathematical horizons can be opened that lend themselves for exploration and problem solving activities. Fourth and finally, we recommend problem solving to be on the 'agenda' of mathematics research in primary education, so that students start to develop problem-solving skills at an early age.

\section{References}

Bakker, A. (2004). Design research in statistics education; on symbolizing and computer minitools. Utrecht: CD-beta Press.

Bos, D.J.P., De Goede, W.H.V., Jansen, R.W., Meijer, H.E., \& Van Streun, A. (1990). Wiskundelijn. Groningen: Jacob Dijkstra.

Dekker, T., Lagerwaard, K., de Lange, J., Limpens, G., \& Wijers, M. (2006). Wiskundige Geletterdheid volgens PISA Deel 1. (Mathematical Literacy according to PISA, vol 1). Arnhem/Utrecht: Citogroup, Freudenthal Institute.

De Haan, D., \& Wijers, M. (Eds.) (2000). Ten years Mathematics Alympiad, the real world mathematics team competition. Utrecht: Freudenthal Institute.

De Lange, J. (1987). Mathmatics, insight and meaning. Utrecht: Freudenthal Institute.

De Lange, J. (2006). PISA: does it really measure Literacy in Mathematics? In E. Schneider (Ed.), Fokus Didaktik (pp. 11-57). München/Vienna: Profil 2006.

Doorman, L.M. (2005). Modelling motion: from trace graphs to instantaneous change. Utrecht: CD-beta Press.

Drijvers, P. (2003). Learning algebra in a computer algebra environment; design research on the understanding of the concept of parameter. Utrecht: CD-beta Press.
Drijvers, P.H.M., \& Doorman, L.M. (1996). The graphics calculator in mathematics education. Journal of Mathematical Behaviour, 15(4), 425-440.

Drijvers, P., Doorman, M., Boon, P., Van Gisbergen, S., Gravemeijer, K. (2007). Tool use in a technology-rich learning arrangement for the concept of function. Paper accepted for publication in the proceedings of the CERME5 conference, February 2007, Cyprus (in press).

Freudenthal, H. (1991). Revisiting Mathematics Education-China Lectures. Dordrecht: Kluwer.

Gille, E., Lagerwaard, K., Limpens, G., de Knecht-van Eekelen, A., Maris, G., \& van Rhijn, C. (2004). Praktische kennis en vaardigheden van 15-jarigen. Arnhem: Citogroep.

Gravemeijer, K., \& Doorman, L.M. (1999). Context problems in realistic mathematics education: a calculus course as an example. Educational Studies in Mathematics, 39, 111-129.

OECD (2003). The PISA 2003 assessment framework; Mathematics, reading, science, and problem solving knowledge and skills. Paris: OECD (http://www.pisa.oecd.org).

OECD (2004a). Learning for tomorrow's world; first results from PISA 2003. Paris: OECD.

OECD (2004b). Problem solving for tomorrow's world. First measures of cross-curricular competencies from PISA 2003. Paris: OECD.

OECD (2005). PISA 2003 Technical Report. Paris: OECD.

Polya, G. (1962). Mathematical discovery. New York: Wiley.

Ruthven, K. (1992). Graphic calculators in advanced mathematics. Coventry: NCET.

Schoenfeld, A. (2007). Add reference to his contribution in this ZDM issue.

Streun A. van (1991). The relation between knowledge and heuristic methods. International Journal of Mathematical Education in Science and Technology, 22(6), 899-907.

Streun, A. van, Harskamp, E.G., \& Suhre, C.J.M. (2000). The effect of the graphic calculator on student's solution approaches: a secondary analysis. Hiroshima Journal of Mathematics Education, 8, 27-39.

Van den Heuvel-Panhuizen, M. (Ed.)(2001). Children learn mathematics. Utrecht/Enschede: Freudenthal Institute, Utrecht University/SLO.

Van den Heuvel-Panhuizen, M., \& Bodin-Baarends C. (2004). All or nothing: Problem solving by high achievers in mathematics. Journal of the Korea Society of Mathematical Education, 8(3), $115-121$.

Werkgroep van advies voor de herverkaveling eindexamenprogramma's Wiskunde I en Wiskunde II vwo (1980). Rapport. The Hague: Staatsuitgeverij. 